\title{
EDUCAÇÃO PARA O TRÂNSITO EM UNIDADE PEDIÁTRICA
}

Ana Cristina Geiss Casarolli ${ }^{1}$, Franciele Foschiera Camboin ${ }^{2}$, Solânia Durman ${ }^{3}$, Claudia Brandelero Rizzi ${ }^{4}$

RESUMO: Estudo descritivo exploratório que teve como objetivo avaliar a aplicabilidade da prática educativa para o trânsito por meio de álbum seriado e software. Realizaram-se atividades educativas, entre novembro de 2010 e fevereiro de 2011, com 41 crianças e adolescentes e, posteriormente foi aplicado questionário avaliativo. Entre os participantes $37(90,2 \%)$ relataram não ter dificuldades em manusear o programa, 40(97,6\%) não acharam difícil participar das atividades, $27(65,9 \%)$ não precisaram de ajuda, 35(85,4\%) acharam a atividade colorida, 32(78\%) relataram não ter participado de outra atividade semelhante e todos conseguiram terminar e gostaram da atividade. Os resultados mostram que a prática educativa, com as estratégias utilizadas, foi eficaz para sensibilizar a população infanto-juvenil para o comportamento seguro no trânsito, e que as estratégias podem subsidiar outras práticas educativas nesse ambiente.

DESCRITORES: Educação; Criança; Acidentes de trânsito.

\section{ROAD SAFETY EDUCATION IN A PEDIATRIC UNIT}

ABSTRACT: This descriptive-exploratory study aimed to evaluate the applicability of educational practice regarding road safety, through booklets with cartoon images and software. Educational activities were undertaken between November 2010 and February 2011, with 41 children and adolescents, following which an evaluative questionnaire was administered. Among the participants 37 (90.2\%) reported not having difficulties in using the program, 40 (97.6\%) did not find it difficult to participate in the activities, $27(65.9 \%)$ did not need help, $35(85.4 \%)$ found the activity colorful, 32 (78\%) reported not having participated in another, similar, activity, and all managed to finish, and enjoy, the activity. The results show that educational practice, with the strategies used, was efficacious in sensitizing the child-adolescent population to safe behavior in traffic, and that the strategies can support other educational practices in this environment.

DESCRIPTORS: Education; Child; Traffic accidents.

\section{EDUCACIÓN PARA EL TRÁNSITO EN UNIDAD PEDIÁTRICA}

RESUMEN: Estudio descriptivo exploratorio cuyo objetivo fue evaluar la aplicabilidad de la práctica educativa para el tránsito por medio de álbum seriado y software. Fueron realizadas actividades educativas, entre noviembre de $2010 \mathrm{y}$ febrero de 2011, con 41 niños y adolescentes y, después, fue aplicado cuestionário evaluativo. Entre los participantes 37 $(90,2 \%)$ relataron no tener dificultades en trabajar con el programa, 40 (97,6\%) no consideraron difícil participar de las actividades, 27 (65,9\%) no necesitaron ayuda, 35 (85,4\%) dicieron que la actividad es colorida, 32 (78\%) relataron no haber participado de actividad semejante y todos lograron terminar la actividad, así como a todos les gustó ella. Los resultados muestran que la práctica educativa, con las estrategias utilizadas, fue eficaz para sensibilizar la población infantojuvenil para el comportamiento seguro en el tránsito, y que las estrategias pueden subsidiar otras prácticas educativas semejantes. DESCRIPTORES: Educación; Niño; Accidentes de tránsito.

\footnotetext{
${ }^{1}$ Acadêmica de Enfermagem da Universidade Estadual do Oeste do Paraná - UNIOESTE.

${ }^{2}$ Enfermeira. Mestre em Enfermagem. Professora do Curso de Graduação em Enfermagem da UNIOESTE.

${ }^{3}$ Enfermeira. Mestre em Assistência de Enfermagem Professora do Curso de Graduação em Enfermagem da UNIOESTE.

${ }^{4}$ Bacharel em Processamento de Dados. Doutora em Informática na Educação. Professora do Curso de Graduação em Ciência da Computação da UNIOESTE.
}

Autor correspondente:

Recebido: 21/02/2012

Ana Cristina Geiss Casarolli

Aprovado: 28/05/2013

Universidade Estadual do Oeste do Paraná

Rua Cipreste, 385 - 85807-700 - Cascavel-PR-Brasil

E-mail: anacasarolli@hotmail.com 


\section{INTRODUÇÃO}

Segundo dados publicados pela Organização Não Governamental Criança Segura, em 2005 os acidentes foram as principais causas de óbitos em criança na faixa etária de um a 14 anos, ficando em segundo lugar as doenças respiratórias e em terceiro as doenças infecciosas e parasitárias. Já para as crianças menores de um ano as afecções do período perinatal prevalecem. No mesmo ano, a principal causa de mortalidade entre crianças até 14 anos foram os acidentes de trânsito, com 2.328 óbitos $^{(1)}$.

A violência no trânsito é caracterizada pelo uso do veículo em vias de acesso que resultam em danos ao ser humano, praticado por pedestres e/ou condutores, podendo ocorrer na forma de acidentes ou crimes no trânsito, poluição ambiental e outros ${ }^{(2)}$. Os acidentes e violências são considerados importantes causas externas de morbimortalidade ${ }^{(3)}$, convertendo-se em sério problema de saúde pública em nosso país, e de acordo com a Organização Mundial de Saúde (OMS); é defendido desde 1955 e foi reafirmado na VIII Conferência Mundial da Saúde, realizada em $1986^{(4)}$.

São vários os motivos para o crescimento do número de acidentes de trânsito na cidade de Cascavel, Paraná. Eles decorrem, principalmente, do aumento significativo da frota e fluxo de veículos, aliados à imprudência, imperícia e descumprimento dos motoristas com as leis de trânsito. Cabe destacar que, entre 2002 e 2011, houve aumento de $96,51 \%$ na frota de veículos. Em 2002 havia 82.319 automóveis e em 2011 havia aproximadamente 161.767; houve aumento de $354 \%$ na frota de motocicletas no mesmo período, em 2002 havia 9.631 e em 2011 havia aproximadamente 34.179. Segundo dados fornecidos pelo Instituto Brasileiro de Geografia e Estatística, decorrentes do censo de 2010, Cascavel possui aproximadamente 286.205 habitantes ${ }^{(5)}$. Esse aumento significativo na frota de veículos impacta, fortemente, na dinâmica do trânsito da cidade, bem como nos tipos e causas de acidentes que ocorrem ${ }^{(6)}$.

Um dos instrumentos que pode colaborar para a redução do risco dos acidentes de trânsito é, também, a educação da população infanto-juvenil. A Educação em Saúde é uma prática social que contribui para o desenvolvimento da consciência crítica das pessoas em relação aos problemas de saúde e estimula a busca de soluções e organização para a ação individual e coletiva. Essa prática rompe com o paradigma da concepção estática de educação como transferência de diretrizes, conhecimentos e habilidades; ela é baseada na participação das pessoas que visam à mudança de situações ${ }^{(7)}$.

A prática educativa que permeia as ações do enfermeiro tem como premissa a participação da população nos serviços de saúde, bem como, servir de instrumento para aproximação da ciência na vida da sociedade ${ }^{(8)}$. Neste contexto, o enfermeiro tem proximidade com a prática educativa em saúde, participando de programas e atividades que objetivam a melhora da saúde da população ${ }^{(8)}$. Assim, a educação para o trânsito, direcionada a crianças e adolescentes, emerge como desafio na prevenção e promoção à saúde da população, fomentando estratégias que promovam a disseminação do comportamento seguro no trânsito, assim como a redução das incapacidades e mortes.

Portanto, os objetivos deste estudo foram realizar atividades educativas que abordassem a educação para o trânsito com crianças e adolescentes e avaliar o uso de um software educativo na aplicabilidade da educação para o trânsito.

\section{MÉTODO}

Trata-se de um estudo descritivo do tipo exploratório, cuja população foi composta por crianças e adolescentes na faixa etária de 7 a 14 anos incompletos, internadas no Alojamento Conjunto Pediátrico de um hospitaç universitário do município de Cascavel-Paraná. A coleta de dados foi realizada durante os meses de novembro e dezembro de 2010 e fevereiro de $2011 \mathrm{em}$ três dias semanais (segunda, quarta e sexta-feira), no período da tarde, na sala de recreação do ACP.

A prática educativa foi iniciada utilizando-se um álbum seriado contendo a apresentação dos objetivos do estudo, frases relacionadas à segurança no trânsito e fotografias que tinham por finalidade a aprendizagem. Materiais como capacete, luvas, joelheira, cotoveleira e cadeirinha foram utilizados para que os participantes pudessem visualizar e se familiarizassem com os equipamentos de segurança. A seguir, foi utilizado um software educativo intitulado "O Jogo de Aprendizado Multidisciplinar (JAM)" desenvolvido pelo curso de Ciência da Computação da UNIOESTE e adaptado para a necessidade desta prática educativa. Seu uso foi avaliado por meio de questionário contendo sete questões direcionadas às características técnicas para sua utilização como: manuseio, clareza de informações, linguagem de interação, tempo de resposta e ajuda na realização da atividade.

Para a análise, os dados foram digitadas em um 
banco de dados, agrupados e contabilizados por freqüência e porcentagens simples. A apresentação dos resultados quantitativos ocorreu na forma de tabelas, gráficos e quadros e discutidos de acordo com referencial teórico pertinente.

O projeto seguiu os preceitos da Resoluções n. 196 de 10/10/96 e n. 251 de 07/08/97 da CONEP foi aprovada pelo Comitê Permanente de Ética em Pesquisa da UNIOESTE sob parecer n. 205/2010.

\section{RESULTADOS}

Participaram da prática educativa para o trânsito 41 crianças e adolescentes. Destes, 26(63,4\%) eram do sexo masculino e 15 do sexo feminino (36,6\%). Em relação a faixa etária, prevaleceu $15(36,6 \%)$ crianças na faixa etária de 9 e 10 anos e foi bimodal para crianças com 7 e 8 anos e entre 11 e 13 anos que apresentaram $13(31,7 \%)$ participantes. Quanto ao grau de escolaridade, $18(43,9 \%)$ crianças estavam no $4^{\circ}$ e $5^{\circ}$ ano, 15 $(36,6 \%)$ no $2^{\circ}$ e $3^{\circ}$ ano e $8(19,5 \%)$ entre $6^{\circ}$ e $8^{\circ}$ anos do ensino fundamental.

Os resultados da avaliação da aplicabilidade do software estão apresentados, parcialmente, na tabela 1. Em relação às dificuldades encontradas, $37(90,2 \%)$ crianças relataram não ter dificuldades em manusear o programa e $4(9,8 \%)$ tiveram dificuldades na interpretação e leitura. Todas as crianças conseguiram terminar a atividade, 40(97,6\%) não acharam difícil participar das atividades que foram propostas e $27(65,9 \%)$ não precisaram de ajuda.

Ressaltamos que das crianças que tiveram dificuldades na interpretação e leitura, 3(7,4\%) delas estavam no $2^{\circ}$ ano sendo que duas tinham 7 anos e uma $(2,4 \%)$ 8 anos e outra cursava o $3^{\circ}$ ano com 7 anos de idade, todas demoraram mais de uma hora para realizar as atividades.

Quanto à característica das atividades, 35(85,4\%) crianças acharam a atividade colorida, 25(61\%) gostaram da prática educativa (jogo e álbum seriado) e $32(78,0 \%)$ relataram não ter participado de qualquer outra atividade semelhante com a desenvolvida.

Quando questionados sobre qual a atividade desenvolvida que mais gostaram, os resultados apontaram que a maioria das crianças gostou das atividades propostas, como demonstrado na tabela 2 .

Em relação ao tempo utilizado para o desenvolvimento da prática educativa a tabela 3 mostra que a maioria dos participantes necessitou mais de uma hora para sua realização.
Tabela 1- Distribuição das questões aplicadas e número de respostas das crianças que participaram da prática educativa para o trânsito. Cascavel, 2011

\begin{tabular}{|c|c|c|c|c|}
\hline VARIÁVEL & SIM & $\%$ & NÃO & $\%$ \\
\hline $\begin{array}{l}\text { Teve alguma dificuldade } \\
\text { em manusear o programa }\end{array}$ & 4 & 9,8 & 37 & 90,2 \\
\hline Achou a atividade colorida & 35 & 85,4 & 6 & 14,6 \\
\hline Gostou da atividade & 41 & 100 & 0 & 0 \\
\hline $\begin{array}{l}\text { Terminou a atividade } \\
\text { no tempo estipulado }\end{array}$ & 41 & 100 & 0 & 0 \\
\hline $\begin{array}{l}\text { Achou difícil a } \\
\text { participação }\end{array}$ & 1 & 2,4 & 40 & 97,6 \\
\hline Precisou de ajuda & 14 & 34,1 & 27 & 65,9 \\
\hline $\begin{array}{l}\text { Já tinha participado de } \\
\text { alguma atividade parecida } \\
\text { com esta }\end{array}$ & 9 & 22 & 32 & 78 \\
\hline
\end{tabular}

Tabela 2- Distribuição das atividades que mais gostaram e número de respostas das crianças que participaram da prática educativa para o trânsito. Cascavel, 2011

\begin{tabular}{lcc}
\hline ATIVIDADES & $\mathbf{n}$ & $\mathbf{\%}$ \\
\hline Álbum Seriado & 4 & 9,7 \\
Jogo & 10 & 24,4 \\
Os dois & 25 & 61 \\
Não respondeu & 2 & 4,9 \\
\hline
\end{tabular}

Tabela 3- Distribuição das crianças de acordo com o tempo gasto para a realização da prática educativa para o trânsito. Cascavel, 2011

\begin{tabular}{lcc}
\hline TEMPO & n & \% \\
\hline 00:00 |- 00:45 & 4 & 9,7 \\
00:45 |- 01:00 & 10 & 24,4 \\
01:00 |- 01:15 & 25 & 61 \\
Não respondeu & 2 & 4,9 \\
\hline
\end{tabular}

\section{DISCUSSÃO}

No estudo houve predomínio do sexo masculino na participação da prática educativa o que pode ser evidenciado em concordância com estudo realizado em Miame-Dade County onde os pesquisadores aplicaram um programa educativo em escolas e participaram na maioria crianças do sexo masculino representando $52,66 \%{ }^{(9)}$. Como foram convidados os pacientes que estavam em atendimento no período de coleta de dados, independentemente do sexo, os autores obtiveram entre os participantes a prevalência de indivíduos do sexo masculino, desta forma este dado não foi influenciado pela adesão.

Os meninos começam mais precocemente a ir 
sozinhos para a escola, brincam nas ruas e próximo a rodovias. Deste modo, a vigilância e a educação para o trânsito com crianças e adolescentes do sexo masculino pode vir a diminuir a exposição destas aos acidentes ${ }^{(10)}$.

Quanto à idade e grau de escolaridade, de acordo com o artigo 76 do Novo Código de Trânsito Brasileiro, a educação para o trânsito deveria ser promovida na pré-escola e nas escolas de ensino fundamental, médio e superior, por meio de planejamento e ações coordenadas entre órgãos e entidades do Sistema Nacional de Trânsito e de Educação, da União, dos Estados, do Distrito Federal e dos Municípios, nas respectivas áreas de atuação ${ }^{(11)}$.

Podemos evidenciar que a maioria, estava na faixa etária de 9 a 10 anos e foi bimodal para as faixas etárias de 7 a 8 anos e de 11 a 13 anos. Porém, esses dados não coincidem com o grau de escolaridade dessas crianças quando demonstra que 15 crianças $(36,6 \%)$ na faixa etária de 9 a 10 anos estavam entre o $2^{\circ}$ e $3^{\circ}$ ano e 8 crianças na faixa etária entre 11 e 13 anos estavam entre o $6^{\circ}$ e o $8^{\circ}$ ano.

A frequência escolar para a faixa etária de 7 a 14 anos era marcante $(97,6 \%)$ em nosso país no ano de 2006. Porém, esse quadro não foi favorável para a faixa etária de 15 a 17 anos. De 1996 para 2006 houve uma redução satisfatória na defasagem do ensino fundamental, esse fato pode ser explicado pela adoção à progressão continuada (aprovação automática). Em 1996 a taxa de alunos do ensino fundamental que estava em defasagem era de $43,9 \%$, essa taxa diminuiu para $25,7 \%$, ou seja, 8,3 milhões entre 32,5 milhões de estudantes. A defasagem escolar é ainda maior nas últimas séries do ensino fundamental. Em 2006, nas quatro primeiras séries a taxa de defasagem era de $20,7 \%$, e nas quatro ultimas alcançava $31,4 \%{ }^{(12)}$.

Para analisar a avaliação do software realizada pelas crianças e adolescentes que fizeram parte do presente estudo utilizou-se alguns aspectos apontados por autores ${ }^{(13)}$. Primeiramente, as facilidades encontradas pelas crianças e adolescentes em manusear o programa, este fator pode estar relacionado com a facilidade na leitura do programa, facilidade de leitura na tela, adequação do programa ao nível do usuário e adequação do vocabulário a população em estudo.

Apesar de grande parte dos participantes da pesquisa relatar não encontrar nenhuma dificuldade, o que evidencia adequação dos fatores, facilidade de leitura do programa e facilidade de leitura da tela ao software, quatro delas tiveram dificuldade na leitura e interpretação das questões inseridas. Essas crianças podem ter sentido dificuldade devido à idade e ao grau de escolaridade, pois são crianças com faixa etária de 7 e 8 anos e que estão cursando o $2^{\circ}$ ou $3^{\circ}$ ano.

A maioria das crianças não teve dificuldade ao responder as questões do questionário e a resolução do software, o que demonstra a adaptação a todas as faixas etárias das crianças e adolescentes que participaram da prática educativa.

Quando questionados sobre a necessidade de ajuda, a maioria relatou não precisar, porém mais de um terço dos participantes relatou precisar de ajuda. Este fato pode estar relacionado à inexistência de manual do usuário e ao fato de estar trabalhando com crianças, sendo necessário explicar sobre o funcionamento do software. Contudo, todos os participantes finalizaram a atividade e 40 relataram não achar difícil participar da prática educativa.

Quanto às características das atividades, a maioria achou colorida e relatou gostar das atividades propostas, esses aspectos estão relacionados com o uso de cor, uso de animações, uso de recursos sonoros, existência de recursos motivacionais e o uso de ilustrações ao desenvolver um software. O software desenvolvido não contêm todas as características acima relacionadas, porém os dados obtidos demonstraram que o aspecto visual foi positivo.

Alguns estudos semelhantes a este foram relatados, entre eles, pesquisadores implementaram um programa, intitulado WalkSafe, de educação para pedestres com crianças de escolas públicas de New Haven, Estados Unidos. Neste estudo, a intervenção educativa ensina a criança a escolher o melhor local para atravessar a rua, a cruzar a rua sempre com a supervisão de um adulto, o que acontece quando uma criança sofre um acidente e qual o melhor momento para realizar o cruzamento. Os autores prevêem que o conhecimento sobre a segurança do pedestre, após a prática, educativa aumente. Considerando os dados alarmantes de acidentes na cidade do estudo, a implementação de medidas que visam melhorar a segurança do pedestre devem ser desenvolvidas, segundo a opinião dos pesquisadores ${ }^{(14)}$.

Diante das diferenças encontradas na aprendizagem das crianças de acordo com o grau de escolaridade, a prática educativa deve respeitar as etapas de desenvolvimento e crescimento da população infanto-juvenil ${ }^{(15)}$.

Os professores e outras agências recomendam que programas de educação para o trânsito façam parte do currículo das escolas públicas da cidade ${ }^{(9)}$. No Brasil, o tema prevenção de acidentes de trânsito já 
é preconizado pelo Ministério da Educação por meio dos Parâmetros Curriculares Nacionais para o Ensino Fundamental como um tema transversal, ou seja, deve ser trabalhado em todas as disciplinas escolares ${ }^{(16)}$.

Segundo o Ministério da Saúde, o período escolar, que compreende o período de 6 a 10 anos, é o momento crucial para se trabalhar educação em saúde, para o desenvolvimento de ações de prevenção e fortalecimento de fatores de proteção tanto individual como coletivo. É neste período que as atitudes e hábitos estão sendo criados e/ou fortalecidos ${ }^{(17)}$.

Neste contexto, a experiência de prática educativa realizada no Paraná, teve como objetivo sensibilizar e estimular sobre a importância do comportamento seguro no trânsito, bem como multiplicar esse conhecimento dentro do círculo social dos participantes. Os encontros consistiram de dinâmicas e aula expositiva dialogada com o tema Comportamento no Trânsito e Noções de Trânsito. Os autores concluíram que a educação em saúde para o trânsito realizada pelo enfermeiro é a principal forma de sensibilizar as crianças a adotarem o comportamento seguro, contribuindo assim, para diminuir os acidentes de trânsito, sendo este um importante agravo a saúde da população ${ }^{(18)}$.

Em um estudo de revisão bibliográfica, que teve como objetivo identificar os critérios de avaliação nacional e internacional para a avaliação de software educacional, os autores apontam aspectos a serem considerados. Entre eles, confiabilidade, manipulabilidade, utilizabilidade e confiabilidade conceitual. Todos os aspectos descritos são fundamentais para avaliar a qualidade do software ${ }^{(19)}$.

Foi possível identificar com o software utilizado para realização da prática educativa o fator confiabilidade, ou seja, a compreensão e manipulação do programa, devido a nenhuma criança ter tido dificuldades na manipulação e compreensão. O subfator manipulabilidade não foi identificado devido ao programa desenvolvido ter sido aplicado somente com as crianças em estudo. $\mathrm{O}$ fator utilizabilidade também foi evidenciado, pois possibilita alterações após sua utilização; e a confiabilidade conceitual, que objetiva a implementação satisfatória e a resposta positiva aos objetivos propostos, também foi uma característica presente no software avaliado.

Quanto ao tempo utilizado para aplicação das atividades propostas, houve predomínio de 45 minutos a 1 hora. Este dado aproxima-se com um estudo desenvolvido em uma cidade do Estado do Paraná onde as autoras realizaram uma prática educativa em uma escola municipal com 8 turmas e 30 alunos. Foram realizados dois encontros que tiveram duração de 2 horas $\mathrm{cada}^{(18)}$.

Ao iniciar a prática educativa utilizou-se um álbum seriado para auxiliar na apresentação do conteúdo proposto. Este álbum também foi utilizado como feedback do conhecimento adquirido pela vivência das crianças e adolescentes e como participante no manejo do software. Os resultados demonstram que as crianças e adolescentes gostaram das duas atividades desenvolvidas (álbum seriado e jogo).

Ao final da prática educativa desenvolvida pode-se observar que os participantes sentiram-se a vontade, pois permaneceram em um ambiente já conhecido, pela realização de outras atividades durante essa permanência na sala de recreação e pela comunicação que se estabeleceu com antes de realizar as atividades.

Outros fatores relevantes a serem mencionados foram as dificuldades enfrentadas para a realização da coleta de dados, pois houve simultaneamente, várias atividades desenvolvidas, com auxílio da recreadora, no mesmo período da realização da prática educativa para o trânsito. Assim, algumas crianças recusaram a participar da coleta de dados por terem outras atividades propostas e algumas por estarem indispostas.

\section{CONSIDERAÇÕES FINAIS}

Por consequência do cenário que alia o aumento da frota com o aumento da população tem-se o aumento do dispêndio financeiro por parte do poder público que se vê compelido a estabelecer medidas adicionais na tentativa de reduzir a taxa de morbimortalidade decorrente dos acidentes de trânsito. E, principalmente, os problemas sociais, físicos e psicológicos dos sequelados e de seus familiares.

Neste contexto, torna-se essencial que os profissionais da área da saúde que atuem nos diversos níveis de atenção à saúde, sejam sensibilizados para trabalhar na prevenção de acidentes de trânsito, assim como nos agravos decorrentes dos mesmos à criança, família $\mathrm{e}$ sociedade. A educação em saúde para o trânsito, como ação de prevenção dos acidentes, deve fazer parte do cotidiano dos profissionais de saúde.

O uso de métodos de ensino variados, como por exemplo as ações propostas pela Polícia Rodoviária, que expõem os carros acidentados nos pátios dos postos de policiamento das rodovias brasileiras, campanhas educativas, propostas de jogos de tabuleiro, softwares, atividades que acontecem nas escolas, eventos e outras 
ações são propostas a serem consolidadas e tornarem-se parte do cotidiano da população, na tentativa de promover a prevenção dos acidentes de trânsito.

O método lúdico auxilia a apreensão do conteúdo e faz com que as crianças e adolescentes, além de passarem a ter uma melhor adesão ao comportamento seguro no trânsito, se tornem agentes educativos no ambiente familiar, escolar e demais espaços de convivência.

É importante também avaliar as práticas educativas realizadas e realizar melhorias nas atividades, propor mudanças e até mesmo reprisá-las ou realizar com outro público-alvo. Cabe reforçar que se deve oportunizar às crianças hospitalizadas atividades educativas que tenham como princípios a prevenção, promoção e recuperação da saúde.

\section{REFERÊNCIAS}

1. Ministério da Saúde. Sistema de Informações sobre Mortalidade. [acesso em 19 fev 2011]. Disponível: http:// www.datasus.gov.br/tabnet.

2. Sampaio EL. Plano de ação e treinamento para o trânsito [monografia]. João Pessoa (PB): Polícia Militar do Estado da Paraíba; 2005. Especialização em Segurança Pública.

3. Martins CBG, Andrade SM. Epidemiologia dos acidentes e violências entre menores de 15 anos em município da região sul do Brasil. Rev. Latino-Am. Enfermagem. 2005;13(4):530-7.

4. Sampaio MJAQ, Amorim MLP, Pessôa ZFC. Acidentes Comuns na Infância e na Adolescência. In: Alms JBB, Ferreira OS, Maggi RS. Fernando Figueira- PediatriaInstituto Materno Infantil de Pernambuco. $3^{\text {a }}$ ed. Rio de Janeiro: Koogan; 2004. p. 1317-9.

5. Instituto Brasileiro de Geografia e Estatística (IBGE). Sinopse dos Resultados do Censo 2010. [Internet] [acesso em 12 set 2011]. Disponível: http://www. censo2010.ibge.gov.br/sinopse/webservice/default.php $? \operatorname{cod} 1=41 \& \operatorname{cod} 2=410480 \& \operatorname{cod} 3=41 \&$ frm $=$

6. Companhia de Engenharia de Transporte e Trânsito (CETTRANS). Estatísticas. [Internet] 2011. [acesso em 25 set 2011]. Disponível: http://www.cettrans.com. br/estatisticas.php

7. Brasil. Fundação Nacional da Saúde. Diretrizes de educação em saúde visando a promoção da saúde: documento base- documento I. Brasília: Funasa; 2007.
8. Oliveira HM, Gonçalves MJF. Educação em Saúde: uma experiência transformadora. Rev. bras. enferm. 2004;57(6):761-3.

9. Hotz G, Marcilla AG, Lutfi K, Kennedy A, Castellon P, Duncan R. The WalkSafe Program: Developing and Evaluating the Educational Component. Trauma inj. infect. crit. care. 2009;66(suppl. 3): 3-9.

10. Martins CBG, Andrade SM, Soares DA. Morbidade e Mortalidade por Acidente de Transporte Terrestre entre menores de 15 anos no Município de Londrina, Paraná. Cienc cuid saude. 2007;6(4):494-501.

11. Brasil. Código de Trânsito Brasileiro: instituído pela Lei n. 9.503, de 23 de setembro de 1997, $3^{\text {a }}$ ed. Brasília: DENATRAN; 2008. [acesso em 02 abr 2011]. Disponível: http://www.denatran.gov.br/publicacoes/ download/ctb.pdf

12. Instituto Brasileiro de Geografia e Estatística (IBGE). IBGE divulga indicadores sociais dos últimos dez anos. Sala de Imprensa: Síntese de Indicadores Sociais [Internet] 2007. [acesso em 12 jun 2011]. Disponível: http://www.ibge.gov.br/home/presidencia/noticias/ noticia_visualiza.php?id_noticia $=987$

13. Campos GHB, Campos FCA, organizadores. Qualidade de Software Educacional. In: Rocha AR, Maldonado JC, Weber KC. Qualidade de Software: Teoria e Prática. Qualidade de software: Teoria e Prática. São Paulo: Makron; 2001.

14. Violano P, Davis KA, Lane V, Lofthouse R, Carusone C. Establishing an Injury Prevention to Address Pediatric Pedestrian Collisions. Journal of Trauma Nursing. 2009;16(4):216-9.

15. Faria EO. Bases para um programa de educação para o trânsito a partir do estudo de percepção de crianças e adolescentes [tese]. Rio de Janeiro (RJ): Universidade Federal do Rio de Janeiro; 2002.

16. Brasil. Secretaria de Educação Fundamental. Parâmetros Curriculares Nacionais: apresentação dos temas transversais, ética. Brasília: Ministério da Educação; 1997.

17. Ministério da Saúde (BR). Secretaria de Políticas de Saúde. Saúde da Criança: Acompanhamento do crescimento e desenvolvimento infantil. Brasília: Ministério da Saúde; 2002.

18. Bova VBR, Wall ML. Educação em saúde no trânsito: uma contribuição da enfermagem. Cogitare enferm. 2005;10(1):60-5. 
19. Veloso BG, Motta MCS. A enfermagem e a qualidade de software educacional: uma revisão bibliográfica sobre critérios de avaliação. Esc. Anna Nery. 2004;8(1):11622. 